\title{
Danza de sombras en la pintura de Louis Soutter
}

\author{
Guillermo Aguirre Martínez ${ }^{1}$ \\ Universidad de Deusto
}

\section{RESUMEN:}

Las pinturas realizadas por Louis Soutter cabe situarlas próximas al Art brut. Lo más característico de sus trabajos tardíos, protagonizados por convulsivas sombras, concierne a su acusado expresionismo. Indagaremos en el sentido precisamente de la sombra y lo pondremos en relación con su significación en el imaginario contemporáneo.

\section{PALABRAS CLAVE:}

Louis Soutter; Pintura siglo XX; Art brut; Arte alienado; sombra.

\section{ABSTRACT:}

When Louis Soutter arrives at a geriatric institution, he begins to paint a serial of dark drawings. These drawings, close to Art brut, are characterized by the continuously presence of histrionic shadows, and by their nearness to an expressionist gesture. We will study the sense of the shadow and we will link it with the contemporary imaginary.

\section{KEYWORDS:}

Louis Soutter; XXth Century Painting; Art brut; Mentally-Ill Art; Shadow.

\footnotetext{
La realización de este artículo ha sido financiada con un Contrato Juan de la Cierva - Incorporación, concedido por el MinisteArio de Economía, Industria y Competitividad (IJCI-2015-26934).
} 


\section{Danza de sombras y significación de la obra}

Las oscuras figuras de Louis Soutter (Suiza, 1871-1942) se desvelan como proyecciones de un particular mito de la caverna, o acaso como negativos de nada, acaso como espectros carentes de lazo con una esfera existencial de la cual nada conocemos. Nos queda, por tanto, adentrarnos en dichas latitudes, prescindir de una luz tan lejana a su imaginario como la sombra lo es respecto de aquellos modelos expresivos -el icono sin ir más lejos- expuestos como pura presencia. ${ }^{1}$ En este sentido, cabe añadir, con Soutter entramos en un aspecto de la condición fenomenológica de la modernidad y de la contemporaneidad en la medida en que la radiación que en el arte suele denotar la presencia de aura, lejos de desaparecer, se nos presenta ahora desde la carencia de luz, desde la plena oscuridad. ${ }^{2}$ Estamos ante una exposi-

Con todo, más adelante hablaremos de la plausible relación entre la sombra y el icono al menos en los márgenes de nuestra época. Señalamos, de antemano, que en este sentido la sombra puede simbolizar asimismo, como en el caso de la luz dorada del icono, lo impenetrable. Señala Uspenski, citando al Pseudo-Dionisio, que “esta 'luz inaccesible' [la simbolizada por el icono bizantino] es 'una oscuridad más que luminosa', cegadora $y$, por tanto, impenetrable. Y el oro, que aúna una luminosidad resplandeciente con la opacidad, expresa de manera adecuada, simbólica, la luz divina: las tinieblas impenetrables, es decir, algo esencialmente distinto a la luz natural, que es lo inverso de las tinieblas" (USPENSKI, Leonid A., Teología del icono, Sígueme, Salamanca, 2013, p. 512). A partir de este comentario, desde la visión que presentamos, comprendemos que estos cuerpos sin luz expuestos por Soutter se ofrecen como imágenes impenetrables, como esencias asimismo, que el artista no encuentra problema en tomarlas, a lo largo del XX, no desde su relación con lo fenoménico sino con lo arquetípico, lugar en el que, siguiendo a Jung, el ser encuentra un vínculo con la divinidad. Nos referimos, por tanto, a una presencia primera, no derivada.

Esto es, su oscura obra no niega el aura sino que se compone precisamente de presencias aureoladas si bien desde su reverso. En ello puede advertirse un ideario latente. Mario Perniola, tras apoyarse en Vattimo e indicar que "el arte sin aura del Posthuman y la crítica sin teoría que la promueve constituirían una aceleración notable de este proceso" [el de la conversión del artista en funcionario del sistema productivo capitalista], concluye que "la reivindicación del aura de las obras del arte y de la autonomía de los mundos simbólicos asumiría, hoy, un significado de contestación social, porque constituiría la última defensa con respecto al dominio total y directo del capitalismo" (PERNIOLA, Mario, El arte y su sombra, Cátedra, Madrid, 2002, p. 78).

Por otra parte, hay que comprender que la sombra, esta misma sombra que Soutter nos presenta, si bien nosotros la tomamos como oscuramente luminosa desde sí ción melancólica de la cualidad numinosa que acompaña o reviste a la obra de arte, ${ }^{3}$ esto es, ante un aura invertida si bien a nuestro juicio existente. Desde ella advertimos que es el sujeto enajenado - aspecto que nos remonta a su vez a la tradición teológica bizantina-, quien permanece vinculado con tales fuerzas, numinosas, en este caso bajo el signo, si se quiere, de lo demoniaco, síntoma, con todo, de una superación de la racionalidad si bien no ceñida, no plegada, a un cauce ortodoxo de pensamiento. ${ }^{4}$

y no derivada de una segunda figura, tiende comúnmente a ser vista, contrariamente a la significación que proponemos, como realidad espuria, como realidad falseada respecto de la forma original. Desde esta comprensión usual de la sombra, en afinidad con otros pensadores como Michel Maffesoli o Henri Michaux, François Jullien, en su trabajo sobre la materia, menciona que esta entidad ha sido históricamente entendida como "sombra de inconsistencia o de la no-esencia, privada como está de su ser por la sola intercepción de los rayos luminosos, pero siempre determinada por la Forma majestuosa, de la cual se separa y a la cual, sumisamente, permanece indisolublemente clavada" (JULLIEN, François. La sombra en el cuadro. Del mal $o$ de lo negativo, Arena, Madrid, 2009, p. 45). Este comentario denota ese carácter secundario que comúnmente se le ha concedido a la sombra hasta el punto de emparejarla, y en ello incide asimismo Jullien, con cualquier cualidad perversa, negativa, censurable, apta para ser reprimida y evitada.

3 El oscurecimiento de la imagen solar, recurrente en Soutter, es una constante en la estética moderna. No se denota con ello una negación sino más bien una inversión, un desplazamiento, una veladura simbólica, la entrada, en fin, en una condición melancólica. Julia Kristeva, en su trabajo precisamente sobre la melancolía, en su capítulo dedicado a Nerval, menciona que "ella metamorfosea las tinieblas en bermejo o en sol que sin duda no deja de ser negro, pero no por ello menos sol, fuente de claridad deslumbrante" (KRISTEVA, Julia, Sol negro. Depresión y melancolía, Wunderkammer, Girona, 2017, p. 168). Desde aquí, desde la condición melancólica de nuestra época, hemos de partir para advertir esta traslación del aura hacia la sombra con base a su identificación de esencia.

4 Siguiendo con esta relación entre el aura y la sombra, entendemos que en un espacio de idealidades veladas la sombra pertenece al ámbito del no-color. Esto es, expone una realidad no fenoménica que, si no es la expuesta por el icono, sí al menos remite a una esencia del yo, a un sí-mismo individual o culturalmente reprimido, soterrado, y que, a fin de cuentas, coincide con la entidad que Martin Buber le reprocha a Jung querer emparentar con Dios. El acromatismo que es la sombra nos devuelve una realidad de mayor hondura que la del mundo fenoménico; en este caso nos traslada a un espacio donde se germina aquello que se proyecta sobre lo real -más adelante hablaremos someramente del punto gris de Klee-. Reverso complementario del aura, participa de la traslación simbólica de un orden metafísico o ideal a uno arquetípico que nuestra época comprende -siguiendo a Jung ante todo (sin olvidar 
Pero continuemos ahora con un recorrido descriptivo en torno a su pintura. Ésta, aun cuando en un primer momento se encuadró dentro del llamado arte alienado y el Art brut, ${ }^{5}$ con el tiempo ha ido cobrando un relieve autónomo, entendiéndose que posee un carácter singular que sobrepasa los márgenes ya de por sí maleables de las aludidas estéticas. Aun así, más allá de la composición desde un supuesto amateurismo, algo que en el caso de Soutter hay que rechazar de raíz dada su previa y elevada formación no sólo pictórica sino asimismo cultural, su obra se observa como un universo singularmente propio aun con rasgos próximos al Expresionismo o incluso al posterior arte gestual. ${ }^{6}$ Su gran aportación, según se

los lazos que guarda con el gnosticismo y la llamada filosofía perenne)-, guste o no, como reducto donde habita la divinidad. Acaso siendo receptivo a este vínculo el sujeto halle en ella o desde ella nuevas idealidades. Nos movemos en el ámbito de una espiritualidad apofática relacionada, subrayamos una vez más, con el no-color: "Cualquier color [menciona Florenski] acercaría el icono a la tierra y debilitaría la visión presente en él" (FLORENSKI, Pável. El iconostasio. Una teoría de la estética, Sígueme, Salamanca, 2018, p. 168). La sombra, derivamos de ello, no hemos de comprenderla en Soutter como cromatismo, como pigmento negro, sino como veladura del aura.

Recordemos que es Jean Dubuffet quien, en 1945, con el afán de proponer una terminología a un modelo de creación que dotase de entidad a los trabajos realizados desde ámbitos marginales, acuña este término. $\mathrm{Al}$ respecto menciona Lucienne Peiry que "las formas artísticas que entusiasman a Dubuffet se sitúan a gran distancia de los modelos culturales tradicionales. Este tipo de obras nacen aisladas y surgen de la exclusión y del enclaustramiento; la fuente de Dubuffet será, pues, el asilo psiquiátrico" (PEIRY, Lucienne, "La aventura del art brut. De la clandestinidad a la consagración”, en Art brut. Genio y delirio, Círculo de Bellas Artes, Madrid, 2006, p. 19). Con todo, la autora no deja de insistir en que los límites del Art brut no quedan ni mucho menos acotados a un ámbito alienado, sino que quedan marcados por otros muchos aspectos. Al margen de su común primitivismo, cada uno de estos artistas puede exponer un modelo estético enormemente variado. En palabras de Peiry, "Dubuffet no circunscribe su campo de investigación a los círculos psiquiátricos. No considera la enfermedad mental como un criterio y no asocia estrictamente el art brut al arte de los alienados" (PEIRY, Lucienne, "La aventura del art brut. De la clandestinidad a la consagración", en Art brut, op. cit., p. 19).

6 "En su producción artística se aprecia indudablemente que no es un extraño en el arte, su competencia técnica resulta evidente y en la obra realizada en el asilo durante los años veinte se percibe cierta semejanza con lo que podríamos llamar genéricamente la 'figuración expresionista' de comienzos del siglo XX, por lo que Soutter es un creador de art brut sólo a medias virgen" (SOLANA, Guillermo, "La suiza visionaria: Wölflin, desarrollará en estas páginas, es tanto simbólica como formal, o en todo caso hay que comprender que, componiendo una unidad indisociable, ambos aspectos exponen motivos estético-existenciales cuya relevancia puede pasar en un primer momento inadvertida si bien describen certeramente el espíritu melancólico de nuestra época. ${ }^{7}$

Al margen de lo apuntado, si bien esto no es extraño en la naturaleza creadora, la obra de Soutter pasa de ser por completo convencional a conformar, a raíz de su aislamiento, un universo propio, dándose incluso en el último periodo, a partir de 1937, un giro rotundo en su modo de pintar, en adelante caracterizado por el uso de los dedos a modo de pincel, lo que inevitablemente deriva en una expresión más nerviosa y directa. Con este universo de formas Soutter nos privará de escuchar, de ver, de palpar incluso, el relieve aparente de sus imágenes. Nos expone un universo velado y, sin embargo, acaso por ello, de una expresividad exagerada. Apagadas, atenuadas, distantes de un plano luminoso de la conciencia, estas sombras se permiten residir en otro orden de realidad, en otros márgenes de existencia. Frente a la angustia de una vida diurna en el que toda acción, toda palabra, es de inmediato incorporada a un canon de codificación que torna lo complejo y plurivalente en unívoco, estas sombras gobiernan en la noche de un espacio adimensional, atemporal: reinas de un ser no ya para el yo consciente -o para el marco social en el que éste se asienta- sino para sí mismas, descondicionadas de lo aparente dado que el cordón que une lo nocturno con lo diurno parece definitivamente roto.

Así por tanto, Soutter presenta un mundo de existencias liberadas de la vida y del

Soutter, Aloïse”, en FAUCHEREAU, Serge (ed.), En torno al Art brut, Círculo de Bellas Artes, Madrid, 2007, pp. 91-92).

Por otra, parte, las figuras que desde 1937 crea empleando los dedos como pincel, son definidas por Thévoz del siguiente modo: "Les silhouettes noires en sont le reflet immédiat et souvent indistinct, comme des ombres chinoises. Un geste, une posture, se détachent parfois en nous donnant une sensation très vive de présence physique" ((THÉVOZ, Michel. Louis Soutter. Rencontre Lausanne, Lausanne, 1970, p. 106).

7 De acuerdo con Thévoz, cuyo estudio es el más logrado de los realizados sobre Soutter, "Il manifeste tous les symptômes de cet état que Freud opposait au deuil proprement dit, la mélancolie: dépréciation de soi, impuissance affective, désintérêt pour le monde extérieur, insomnies, refus de se nourrir, etc." (THÉVOZ, Michel. Louis Soutter, op. cit., 1970, p. 22). 
vivir, de la muerte y del morir, un mundo de formas desligadas de la conciencia del sujeto y de la percepción que el otro realiza en torno a aquél. Sus figuras son en cierto modo burlas, son las siluetas que, liberadas de un ser normativo, nos desafían, nos exponen su estar fuera de nuestro mundo ordenado aun a costa de un exagerado aislamiento. Pero este quedar fuera de los límites de la razón a su vez las protege. Ahí donde enraízan -esto es, en sí mismas en tanto que carecen de contexto (y aquí una vez más resulta posible ponerlas en relación con el icono, exento de mundo fenoménico, si bien en este caso desde su reverso melancólico)-, en modo alguno podrán ser dañadas, tampoco enjuiciadas ni exoneradas de una hipotética culpa -la de la alienación del pintor-, pues donde no hay categorías no hay atributos del ser sino meramente realidades vivientes. Recordemos en este punto que, en nuestra cultura occidental, la mencionada melancolía -desde el Barroco metódicamente- se vincula con la ausencia de Dios o al menos con la incapacidad del ser, como observamos en la conocida imagen de Durero, para posibilitar un encuentro. Este inframundo de Soutter es, una vez desplazado al sanatorio de ancianos en el que se vio recluido, el único reino posible donde respirar sin sentirse envenenado, si bien esta visión, como resulta común comprender, encuentra inconvenientes y puede ser observada desde alguna otra perspectiva. Recordemos, en todo caso, que en nuestra interpretación partimos de una condición melancólica, saturnal, de su pintura.

Desde este último aspecto hemos de seguir insistiendo en la significación de la sombra, de la pérdida del color, propia de la época en que el artista suizo realiza sus trabajos. Por un momento obviaremos la situación emocional de Soutter, a la cual más adelante nos referiremos, para aludir a una realidad más amplia que conviene mencionar. Cabe así hacer referencia a un hecho fundamental que sobrevuela esta primera mitad del pasado siglo en la que nos movemos. Es sabido que la crisis formal-racional que asoló nuestra cultura a partir de finales del XIX repercutió en una crisis espiritual en tanto que forma y contenido componen un mismo molde. Esta crisis formal, que llevará a la disolución de estructuras bien asentadas en nuestros esquemas de pensamiento y emoción, y que en el caso del arte conducirá ante todo a la fragmentación denotada, entre otros elementos, por la pérdida del volumen $^{8}$ y la línea -si bien el proceso no es progresivo, claro está-, va a conducir a un arte desorganizado o, mejor dicho, organizado de modo diferente al dominante hasta ahora, con el surgimiento de los ismos, la desconfianza en la lógica del lenguaje o, en fin, en la sintaxis convencional de toda expresión estética. Como en la poesía, como en la música, la pintura sustituirá la primacía de la línea por relaciones cromáticas, guiadas por fundamentos compositivos a primera vista menos evidentes. De acuerdo con esto último, y tal y como expondrán creadores como Klee, Kandinsky, etc., cuyos métodos compositivos quedan ceñidos a leyes íntimas, orgánicas, naturales, no puede hablarse de una disolución sin más sino de un proceso de reordenación, de preponderancia del material vivo de la pintura sobre el superficial, o al menos de recuperación del objeto indecible, invisible, ${ }^{9}$ cuya bisagra con lo fenoménico es en Klee el punto gris, axis mundi donde podemos hallar el encuentro/ desencuentro entre el aura y la sombra. ${ }^{10}$ De este modo, el vínculo de esta expresión con la función iconológica sigue abierto en tanto que, cada cual a su modo, se desea insinuar cuanto trasciende a lo fenoménico, sin que entremos aquí a debatir la naturaleza de dicho objeto.

Vayamos, más allá de estas relaciones, directamente al aspecto que nos interesa en relación con la obra de Soutter si bien vinculando

\footnotetext{
Recordemos que esta pérdida de volumen queda vinculada con su sustitución por una expresión plana. El presente fenómeno cabe ponerlo en relación con el despojamiento de una de las aristas de la llamada cuaternidad -que en este caso vendría a emparentarse con la sombra-, de modo tal que el abandono de lo sustancial, de lo telúrico, la presentación de lo real de modo racional o aparentemente irracional si bien de manera falseada, no afecta a la pintura de Soutter-como tampoco al Art brut-, que no despoja a la expresión estética de su fundamento, de esa sustancia que en el caso de la música hemos de identificar con el silencio, con un silencio, cabe añadir, como en el caso de estas sombras, no subsidiarias de una primera realidad, sino densos de sustancia, de una entidad, en fin, comprendida como primera sustancia de lo existente, o al menos como puerta de acceso a lo fenoménico,

9 Remitimos en este aspecto, desde una relación con la pintura de Kandinsky, a: HENRY, Michel. Ver lo invisible. Acerca de Kandinsky. Siruela, Madrid, 2008.

10 En relación con este punto gris, escribe Klee: "Ese ser-nada o ese nada-ser es el concepto no conceptual de la no contradicción. Para llevarlo a lo visible (tomando al respecto una especie de decisión, estableciendo algo así como el balance interno), es preciso apelar al concepto de gris, al punto gris, punto fatídico entre lo que deviene y lo que muere". (KLEE; Paul. Teoría del arte moderno. Cactus. Buenos Aires, 2008, p. 55).
} 
nuestras consideraciones con el fenómeno de mayor amplitud que venimos abordando. Siendo concisos, hemos de advertir que la pérdida de la línea, la pérdida también de profundidad -sintomáticos ambos de un cambio de cosmovisión y denotativos de una nueva relación del ser con un ámbito no fenoménico-, la crisis de la forma y del lenguaje, denota un socavamiento no sólo de la forma sino en primer lugar del contenido, la sustancia que la conforma, lo que en las artes vendría definido por tanto no sólo por una desconfianza de cuestiones como la perspectiva, la sintaxis, la tonalidad, etc., sino por una crisis del material mismo constituyente del objeto, crisis, en consecuencia, de la significación, crisis de los fundamentos de todo objeto expresivo, crisis incluso del sentido de utilidad en el caso de la arquitectura -que incidirá en la oposición entre arquitectura y edificación-, y en lo que en relación con Soutter nos ocupa, crisis de la luz como elemento simbólico, como elemento capaz de dotar de voluntad de forma a una realidad inefable, sin que se defina ésta pero tomándola como sentido de toda expresión estética. Reiteramos que creemos que no es éste el momento para profundizar en ello, si bien queremos dejar claro, pues es básico para seguir el desarrollo de nuestra exposición, que la crisis de la forma no ha de disociarse de la crisis de la sustancia y del sentido del arte: todo ello forma parte de un proceso de licuación mayor que transciende obviamente lo estético y, llegando a Heidegger -y en ello incidimos en la cuestión del volumen, que a su modo tocará Jung en otro orden de cosas-, se pliega a lo que podríamos llamar -seguimos insistiendo dada su gravedad- crisis del fundamento. ${ }^{11}$

Proponemos, dado lo complejo de lo expuesto de modo sucinto, quedarnos con que en el momento en que este giro completo de las ideaciones humanas occidentales no acaba de revelarse enteramente, la pintura de Soutter, quizás desde su condición de sujeto socialmente enfermo, expone ya el paradigma que hoy define el estado existencial de nuestra cultura. Es éste, por tanto, un aspecto clave a la hora de ponderar su obra, más si cabe cuando, a pesar de su capaci-

Tocamos en este punto uno de los motivos axiales de este trabajo, vinculado, como dijimos, con el ethos melancólico, con la inversión de la luz por la sombra, pero a su vez desde la comprensión usual -no en Soutterde esta última como subsidiaria de aquélla. Si reivindicamos la realidad del aura o la de la sombra es desde su valor de fundamento, de realidad no fenoménica que sostiene al hecho estético. dad para interpretar los tiempos, su trabajo hubo de ser rescatado de un hipotético olvido. Hemos de recordar en esto el papel excepcional que Le Corbusier, desempeñó en esta tarea, ayudándose más delante de, entre otros, Jean Giono. La validez de la obra de Soutter deviene ante todo de su simbolismo visionario, y esto es algo que rebasa incluso el valor de su calidad formal, más si cabe cuando belleza y simbolismo o verdad se separan -podríamos en este momento ampararnos en Kant pero lo cierto es que la crisis surge en el Renacimiento y domina ya a lo largo de la estética barroca- de manera abrupta. La expresión de Soutter expone con paradójica lucidez las derivas de una época. Hablando de modo laxo, pero asimismo significativo, diremos que expone a su manera, o reformula, invierte, el mito de la caverna.

\section{Le Corbusier, Soutter, Holliger}

Antes de continuar con la significación de su trabajo e incidir en el sentido de la sombra, mencionaremos que el desarrollo artístico de Soutter es verdaderamente particular y merece la pena destacarse aun con un par de pinceladas. Nacido en 1871 y fallecido en 1942, sus aspiraciones primeras se centrarán en la arquitectura, si bien en 1892 abandona sus estudios para dedicarse a la música. Discípulo de Ysaye, en 1894 conoce a su futura mujer, Magde, asimismo alumna del célebre violinista. Poco después, da un nuevo giro a sus planes y se vuelca en la pintura y el diseño, primero en Suiza y luego en París, para finalmente marchar junto a Magde a Estados Unidos - de donde ella procedía-. Tras una época de titubeos, acaba ejerciendo como director en el departamento de bellas artes del Colorado College. Más adelante, en 1903, alegando serios problemas de salud mental por parte de su marido, Magde le pide el divorcio y Soutter regresa a Europa, donde tras un intervalo de unos pocos años acabará por instalarse en Suiza destacando como violinista. Pese a ello, sus problemas mentales se irán agravando hasta que, finalmente, obligado por su familia, ingresa primero en un sanatorio para enfermos mentales y ya en 1923 en un asilo para ancianos en la localidad de Ballaigues. ${ }^{12}$ Es entonces cuando, en el lapso de los

12 Será la familia de Soutter quien lo obligue, en 1923, a internarse en la residencia para ancianos donde perma- 
veinte años que transcurren hasta el momento de su muerte, en 1942, lleva a cabo la obra que de él nos interesa.

Su expresivo trabajo, en fin, se enmarca en el periodo que dura su reclusión en Ballaigues, y si bien, como ya señalamos, en un inicio su creación se quiso encuadrar dentro del arte alienado y el Art brut, hoy en día se le considera un artista con entidad propia, por completo singular, y difícilmente adscribible a un movimiento concreto. Con base a su difícil encuadre, con base al hermetismo de su trabajo, cualquier apreciación podrá resultar válida, sí, pero sin duda insuficiente. Desde nuestro mundo enmascarado y falseado, podemos tan sólo percibir una sombra de sus sombras. Advertimos por ello que ese espacio subterráneo desde el que sus extravagantes y oscuras figuras se convulsionan y abrazan, juegan, gritan y dialogan, posee para el pintor una mayor densidad existencial, casi mitológica, que la realidad anclada en ese otro estrato desde el que por lo común proyectamos nuestra mirada, ${ }^{13}$ y que si todas esas figuras se presentan bañadas en sombra no es en verdad desde una apreciación al uso - pues se revelan poseedoras de luz en tanto que la oscuridad es su propia luz- sino desde nuestra opaca visión, desde nuestro eclipse perceptivo.

Aquello que nos presenta Soutter no es, por tanto, una sombra devenida de ausencia de luz, sino que la sombra misma posee su particular luz, es el componente que aporta profundidad, expresión, sentido, a su pintura, quedando lo hipotéticamente iluminado, en contraste con nuestra perspectiva, como realidad deficiente, velada, apagada, plana, desprendida de la vida y oprimida hasta la asfixia por todas las categorías que el sujeto ha construido hasta acabar por mutilarse. ${ }^{14}$

neció hasta su muerte.

13 "Each individual figure is charged magically and receives a mythical dimension. The active figures are transformed into moving stick figures" (ZUTTER, Jörg, "Louis Soutter", en Louis Soutter: Fingermalereien 1937-1942, Galerie Karsten Greve, Köln, 1998, p. 22).

14 La imagen de un eclipse que empaña nuestra visión la expone Buber con relación a la idea de Dios. Puede, no obstante, extrapolarse a cualquier realidad eidética: "Un eclipse del Sol es algo que tiene lugar entre el sol y nuestros ojos, no en el Sol mismo" (BUBER, Martin, Eclipse de Dios. Estudios sobre las relaciones entre religión y filosofía, Fondo de Cultura Económica, México D.F., 1993, p. 31).
Vinculados aún con el mundo musical, comprendemos también que cuando Heinz Holliger dota de cuerpo sonoro a las formas de Soutter en su Concierto para violín (Hommage à Louis Soutter), ${ }^{15}$ participa de esa misma liberación existencial, si bien, claro está, lo que para el pintor posee un sentido articulado aun desde parámetros no necesariamente racionales, para el músico, en la interpretación que hace de sus pinturas, no puede sino construirse desde la reconstrucción, incluso la artificialidad, que hace de lo caótico un lenguaje expresivo deliberadamente medido. No nos adentraremos por estos terrenos pues resultan dados a luchas dialécticas, pero comprendemos pertinente resaltar que se da una diferencia cualitativa -simbólica- en la obra compuesta desde el desprendimiento racional y aquella que, aun desde la intuición, plantea exponerse a modo de réplica, retrato o diálogo, de un mundo indescifrable. Más allá de estas puntualizaciones, con su homenaje, Holliger, no hemos de negarlo, acepta la invitación de esas sombras y desciende o trata de hacerlo por unos momentos a un mundo de realidad $\mathrm{y}$ vitalidad en principio carente de equilibrio y de medida. Es aquí, en estos estratos soterrados, donde la vida se manifiesta como rebelión contra esa otra existencia que hemos construido a modo de segunda realidad -la diferencia no es de grado cuantitativo sino cualitativo, reiteramos-.

De acuerdo con esto último, si el ser es en palabras de Heidegger 'ser para la muerte', lo es, en lo que nos ocupa ahora, precisamente como consecuencia de haberse desmembrado de la naturaleza y haber sobreimpuesto sobre esa primera realidad un falseado mundo de doctrinas y conceptualizaciones que le llevan de ser en sí a ser para otra entidad. ${ }^{16}$ Una mampara cultural,

15 Este concierto lleva por subtítulo Homenaje a Louis Soutter: HOLLIGER, Heinz, Violinkonzert 'Hommage à Louis Soutter'. Thomas Zehetmair, SWR Sinfonieorchester Baden-Baden und Freiburg, ECM, München, 2004. Cabe señalar esta vez con mayor detalle, que Soutter, en el periodo anterior a su sepultura mundanal, destacó como violinista de la Orquesta del Teatro de Ginebra, precursora de la actual Orquesta de la Suiza Romanda. Previamente había estudiado e incluso se había ganado la admiración de Ysaÿe. Cuando a Holliger se le encarga una obra para celebrar el septuagésimo quinto aniversario de la OSR, se deja guiar por una serie de conexiones en cuyo centro encontramos la figura, la sombra si así se quiere ver, de Louis Soutter.

16 Podríamos hacer referencia a la presentación de su imagen de Cristo en la cruz como una vision del propio pintor de sí mismo aherrojado por un orden moral del 


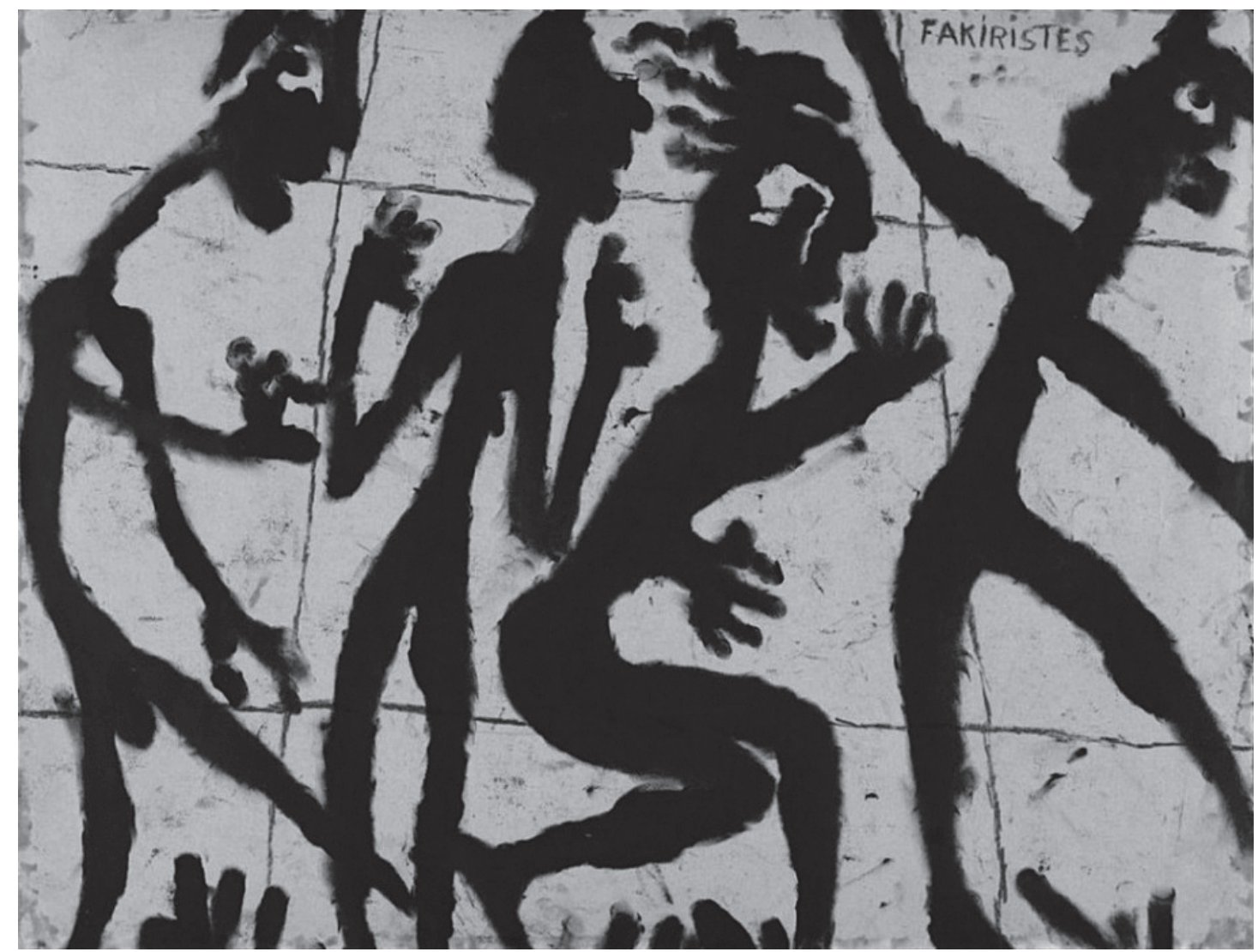

Fig. 1. Louis Soutter. Fakiristes, 1937-1942. Tinta sobre papel.

un verdadero eclipse de nuestra mirada, nos deslinda de nuestros afectos, vivencias elementales $\mathrm{y}$, sin que quepa separarlas de éstas, de nuestras necesidades metafísicas - posean la naturaleza que posean-: suprimidas las últimas, racionalizadas en exceso, el sujeto se torna paradójicamente pasto de sus propios dioses, en este caso pasto de sus propios temores. Y es que desde esta comprensión, podríamos llegar a afirmar que es el miedo el que aleja al hombre de unas coordenadas existenciales acordes con su ser, y que su misma incapacidad para abandonar su mundo de ilusiones y desilusiones cotidianas es la que le mantiene atado, condenado, a un árbol cuyas ramas crecen y crecen sin alcanzar la luz del día, del mismo modo que sus raíces se ven incapaces de alimentarse de una húmeda y fértil tierra: un árbol, en fin, llamado a alzarse y a desplomarse quedando nosotros bajo él.

que, ya en los cuadros en que las figuras danzan y corren, se ve jubilosamente liberado: "Soutter struggles with ethical values and Christian ideas about morality. As if possessed, he ferrets out, primitive image patterns in the search for archaic motifs" (ZUTTER, Jörg, "Louis Soutter", en Louis Soutter, op.cit, p. 22).
Según nos parece, el mundo de Soutter posee una intensidad vital, afectiva, en exceso abundante para lo admitido por nuestra sensibilidad. Ésta, condicionada por el aludido eclipse que la distancia de lo real, es ciertamente la que percibe su mundo como sombrío, sin reparar en que si así se nos revela es, en primer lugar, debido al crepúsculo desde el que, a fin de cuentas, se proyecta nuestro mirar atrofiado. ${ }^{17}$

\footnotetext{
7 Resulta más que interesante la identificación que Daniel Naegele realiza entre una fotografía de Brassaï y la obra de Soutter. Esta equiparación Naegele la proyecta a su vez sobre la arquitectura de Le Corbusier - primo de Soutter-. Al respecto, para quien desee continuar estableciendo relaciones, se ha de recordar que el propio Soutter, antes de dedicarse y destacar como violinista, realizó estudios de arquitectura. Regresando a la imagen de Brassaï, lo que más llama la atención de ella es que muestra en primer lugar dos cavidades rocosas que a la mirada del espectador asemejan las cuencas de un cráneo. Más allá se distingue un paisaje, si bien lo interesante reside en la distinción entre un ver a partir de la mirada, y un ver la propia mirada, esto es, un vernos viendo, un ver desde el ojo y no a partir de él. Todo ello, por supuesto, se ha de vincular con la idea de autoconciencia, axial en toda época reflexiva tal y como lo es la nuestra. Dejemos que lo explique
} 
De esta manera entendido, hemos de comprender que o bien el mundo de la caverna es aquél sobre el que nosotros nos asentamos, o bien que, aun siendo el de Soutter el que en verdad se desarrolla 'bajo tierra', se presenta como contraparte verdaderamente vital de este otro mundo en el que nos vemos recluidos. Regresando aún a Holliger, entendemos por consiguiente que las constantes disonancias que llegan a nuestros oídos y los dañan con denuedo, son, como las sombras del pintor, ecos lejanos, sonoras ondas veladas o últimas remanencias de un mundo del que, si ya no formamos parte de él, no es como consecuencia de haber sido rechazados sino de habernos alejado voluntariamente. ${ }^{18}$ Nuestro ser histórico, ser cultural, así lo impone, y quien guarda el valor de regresar a la 'barbarie' - caso de Soutter-, necesariamente ha de verse desplazado de este mundo de espectros obsesionados en comprender todo fenómeno desde su valor superficial.

el propio Naegele: "Nosotros, los espectadores, somos los moradores de la cueva a los que se refiere el título. Brassaï nos ha colocado dentro de este antiguo habitáculo, obligándonos a mirar hacia el exterior. Pero quizá por su tamaño real sobre una hoja impresa, la fotografía implica mucho más que eso. Al mirarla nos da, a su vez, la espalda. Las elipses son ojos completos, con pestañas, con agudos 'entramados venosos' y con pesados párpados inferiores. Sin embargo, la concavidad de la imagen rechaza esa interpretación de la cueva como objeto opuesto a nosotros. La cueva nos rodea. Está claro que no estamos mirando ojos; estamos en el interior, mirando a través de ellos" (NAEGELE, Daniel, "Drawing-over: Une vie decantée. Le Corbusier y Louis Soutter", en Revista de arquitectura, vol. 6, Navarra, 2004, p. 43).

18 Podríamos decir que obviamente la pérdida de entidad de la realidad no es asunto de la realidad, neutra, sino de nuestra negativa a conformar ideaciones acordes con nuestra época: "Toda realidad es necesariamente una realidad cualquiera, a la vez determinada y fortuita, luego insignificante. Decimos también: cuando se atribuye un significado a lo real se le presta un valor imaginario, un valor añadido a la percepción de la realidad, la cual puede siempre interpretarse en términos de mero azar". De acuerdo con Rosset, "devolver la realidad a la insignificancia consiste en devolver lo real a sí mismo: en disipar los falsos sentidos, no en describir la realidad como algo absurdo o carente de interés" (ROSSET, Clément, Lo real. Tratado de la idiotez, Pre-textos, Valencia, 2004, p. 56-57). Todo ello, en nuestro caso, lo ponemos en relación con la idea de que la insignificancia de la realidad subraya sin embargo, contrariamente, la posibilidad de lo real, y que esto posible es la condición, es la naturaleza, volviendo a Klee y Kandinsky, de lo oculto o absoluto. La sombra de Soutter se aproxima más a este ocultamiento, lo desvela tanto o más, que la manifestación cromática de lo real.
Holliger, por consiguiente, a la hora de dotar de forma musical a las pinturas de Soutter, vaciará sobre nuestros oídos unas ásperas sonoridades afines a las que el pintor nos presenta visualmente, un lenguaje disuelto, desorganizado, no ceñido a un orden lógico, una confrontación de unas voces con otras donde, recalcamos, cuanto nos interesa es su valor como símbolo, más veraz en Soutter que en Holliger. Sólo desde estas disonancias, desde un estrato prelógico, sólo desde la caverna sonora, óptica y existencial, puede el sujeto exponer una pulsión descondicionada, existente en sí y para sí, un latido de naturaleza esencial desde el que, en adelante, resulte posible -de darse esto así- construir un mundo de ideaciones. Cualquier otro intento de sublimar la realidad al margen de lo telúrico se comprenderá tan imposible como falso. Sólo tras haber descendido a ese reino en principio de sombras puede el sujeto 'rescatar' la mirada desde la que participar de la realidad desde sí misma y no desde su eclipse, aun cuando, cabe añadir, descender a este mundo no presupone el regreso. Sin adentrarnos en una materia que no concierne a los aspectos esenciales de este trabajo, remitimos aquí, por cuanto pueda sugerirnos, tanto a Ulises como a Orfeo, tanto a Dante como a las escenas, con la mujer arrodillada en primer lugar como símbolo nuclear que es, de la pompeyana Villa de los misterios.

El desorden deja paso al orden tomando de éste no nuestra construcción habitual, sino aquellas otras posibilidades desde las que un distinto modo de estar y de percibir se incorpora al mundo, al mundo del arte asimismo, para denotar que no uno sino múltiples, son los tipos de organización y, en consecuencia, de percepción y racionalidad expuestos incluso a un mismo tiempo. En este mismo sentido, podemos ir más lejos en nuestras indagaciones aun desde el imperativo de detenernos de inmediato para no salirnos en exceso de nuestros márgenes, y así advertir que en estas expresiones tan infrecuentes a nuestras percepciones habituales, la obra de Soutter, como la de Holliger, se aproxima, juega, con una libertad propiamente expresionista donde cabría hablar de conceptos como polirritmia o polimetría que emparentarían -nada extraño, en cualquier caso- su arte con expresiones canónicamente asentadas en culturas del oeste del África subsahariana -extendidas, con el tiempo, a otras latitudes-. Esta liberación del ritmo, común al Expresionismo 
del que Holliger, en la distancia, participa, resulta tan patente en Soutter que no puede mirarse su pintura sin atender a su vínculo con la danza. Desde ella podríamos hacer referencia a sus ritmos plásticos para emparentar sus figuras con -realizando un salto mortal- las encontradas en la cultura fon, epicentro junto a la yoruba de la rítmica en cruz (superposición de la polirritmia con la polimetría). Se trata de un patrón nada extraño que se introducirá en el arte musical -ante todo por medio del jazz-, plástico -Action painting- y hasta poético -siendo Senghor su principal teorizador- a lo largo del XX y que en este momento hemos comprendido interesante mencionarlo.

\section{Rorschach}

Cuanto presenciamos en estas sombras que nos revela Soutter, aquello que captamos desde nuestro condicionado mirar, es en primer término unos compulsivos movimientos. Desde éstos intuimos unos estados emocionales, unas primitivas reacciones disociadas de nuestra existencia habitual -si bien con ello exponemos, como si de un test de Rorschach se tratase, las formas de nuestro espacio interior-. De todo ello nada conocemos pues nuestra capacidad para sentir, para empatizar asimismo, se advierte tan embotada que a la menor afirmación por nuestra parte no haríamos sino definirnos a nosotros mismos. Tratar de adentrarnos en un mundo de pulsiones aculturales o propias de otros órdenes de pensamiento -ni siquiera habremos de acogernos al término de 'órdenes culturales', liberándonos, en fin, de este marco conceptual-, desde nuestro filtro racionalista resultaría comparable a tratar de comprender un mundo irracional desde parámetros racionales. Dicha tarea nos parece adulterada además de insuficiente, residual. Nada sabemos, hemos de asumir, del motor de los movimientos anímicos de estos crípticos seres que Soutter traza en su etapa más sorprendente por medio de sus dedos $;^{19}$ tan sólo captamos sombras y rellenamos con nuestra sustancia el interior delimita-

19 "Soutter finger-paintings are associated with his intentionally barbaric, primitive style, which is enthused by poverty. Finger-painting is simply painting without tools. Painting is done directly with the skin. In my own art, it comes from a critical engagement with the concept of body art and gestures" (MENNEKES, Friedhelm., ARNULF, Rainer, "About Louis Soutter" en Louis do por sus contornos, sin que ello nos revele nada en sí sino ante todo algo de nosotros pues no poseemos el grado existencial óptimo para participar de su misma realidad, o de poseerlo lo mantenemos sepultado.

Desde esta perspectiva cabe añadir que, así como por nuestra parte impedimos al pintor el acceso a un mundo de realidades convencionales pues el peaje que éste habría de pagar podría llevarle a descomponer su propia naturaleza, cuanto Soutter exige de nosotros es el abandono de toda lógica a la hora de captar el fondo de su telúrica pintura. Desde una cierta equivalencia, podría argüirse que de igual manera que en el caso del sujeto 'diurno' éste se ha de exiliar de sí para acceder a un lugar a su mirada oscurecido, aquello que dicho sujeto 'diurno' demanda del sujeto subterráneo concierne a una salida de su sí-mismo y, por correspondencia, de su naturaleza prelógica. El abandono de un orden natural de mediciones, en fin, es la exclusiva condición para poder tomar parte de este universo de ritos y bailes, alegrías y tristezas: desprenderse, distinguirse, de un orden de cosas alienante que, en su hipertrofia, torna al sujeto en pieza de un engranaje productivo.

Pero la esfera estética todo lo renueva al menos o incluso desde sus lugares marginales, de manera que estas formas nos devuelven especularmente, además de limpias, las densas -en cuanto que vivas- realidades que habitan, que conforman y dominan el espacio del creador, esas mismas que en el anterior punto advertíamos desde la obra de Holliger y que había que entender, al fin y al cabo, como caóticas para el oído cotidiano pero no así para la sensibilidad del sujeto enraizado en un orden arraigado en un distinto estado de percepción, aquél que nosotros por convención denominamos irracional, enajenado, aun cuando, como sabemos, y dejando de lado situaciones patológicas patentes, en ocasiones el sufrimiento y la actitud del alienado devienen de una coacción social que lo obliga a confrontar su mundo de ideas con el común racional; un sufrimiento, en suma, motivado por su impotencia a la hora de reivindicar que una mirada hacia el mundo distante de la acostumbrada puede ser tan válida como veraz.

Continuando con nuestro tema, cuanto se comprende desde estas imágenes es ante todo un lazo roto entre la superficie y las honduras,

Soutter: Fingermalereien 1937-1942, Galerie Karsten Greve, Köln, 1998, p. 53). 
una simbiosis estética imposibilitada de antemano dado que nuestro orden en exceso racionalizado -limitante con lo neurótico- rechaza, no asume, aquellas sustancias elementales, reparadoras, sin las cuales la vida queda partida por su mitad. Nos situamos con ello, desde esta disociación entre lo sano y lo enfermizo, en uno de los conflictos del sujeto occidental actual, por momentos más y más ceñido a una lógica, a un deseo de conocimiento especulativo de todo cuanto forma parte de su entorno, y a la supresión bien de aquello que queda fuera de sus posibilidades de visión, bien de aquello que participa de la realidad desde otros cauces, desde otras mediciones, desde otras imágenes. El deseo forzado de adecuación de éstas a un orden común daña la personalidad del sujeto marginal suponiendo una crisis inmediata y su consucuente existencia desplazada.

Prosiguiendo con esta dualidad, conformada por un mundo especulativo duro, pétreo, convencionalmente aceptado, por una de sus caras, y dinámico, no controlado ni controlable, por la otra, determina el universo completo de todo creador siempre que, como ocurre en el caso que nos ocupa, el hilo que aúna un espacio germinal con el del observador no quede en algún punto cercenado. Con base a ello, el mundo proyectado por Soutter llega hasta nosotros ya sin palabras, mudo, desfigurado, es cierto, si bien hemos de preguntarnos si dicha ruptura, si dicha distancia, se debe más a una imposibilidad del artista por acercarnos su mensaje, a una negación del sujeto creador a la hora de participar de nuestro orden de vivencias, o por el contrario si somos nosotros quienes, con un portazo, cerramos toda opción de encuentro entre un universo y el otro. Cuanto cabe al menos barajar, en lo tocante a nuestra incapacidad para acceder a su esencia, es la posibilidad de que ese mundo primordial no queda distanciado del que hallamos en las pinturas de Lascaux o de cualquier otra cueva paleolítica o neolítica cuidadosamente trabajada. ${ }^{20}$ Más próximas a nosotros, y más lejanas a Soutter -y partimos en esto del vínculo que podríamos encontrar desde un lazo formal- serían en cambio las imágenes características de las cerámicas grie-

$20 \quad$ "Soutter rigorously refused all cultural influences and realized a latest creative energy beyond tradition in unusually suggestive works which appeal to a primitive human sensibility which is enriched by archaic phantasies" (ZUTTER, Jörg, "Louis Soutter”, en Louis Soutter, op. cit, p. 21). gas de figuras negras o incluso rojas. En este caso se exponen aproximaciones a lo real que, aun presentadas por medio de sombras, hemos de tomarlas asentadas en unos niveles de racionalidad más afınes a los hoy cotidianos, si bien no podemos dejar de lado el hecho de que, partiendo de las consideraciones de Nietzsche en torno al arte griego recogidas en El nacimiento de la tragedia, se ha de comprender que incluso tales figuraciones se presentan como sustratos primeros colindantes con el mito -espacio, como es sabido, de ambivalencia-. Más allá de estas comparativas ha de añadirse que, con su mayor o menor nivel de profundidad, todo arte no espurio se nutre, siguiendo a Nietzsche, de un componente dionisíaco que desborda los niveles cotidianos de percepción de lo real lindando así con un orden sacro. ${ }^{21}$

Ahora bien, si como suponemos el orden elemental, existencial, no ha variado en exceso mientras que el cultural sí lo ha hecho y en grado notable, resulta evidente que Soutter nos está mostrando con su obra, como Holliger con la suya, la condición del artista, del creador de imágenes -aquél que toma el camino de Orfeo para volver o, de no resultar posible o no deseable, permanecer ahí donde ha llegado- contemporáneo, dado que se ve irremediablemente recluido en el espacio desde el que nos habla, desde el que nos grita, abandonado, desgarrado más y más a medida que la sociedad pone una mayor y casi insalvable distancia entre el orden de los fenómenos primordiales -aquél desde el que se expresa el sujeto creador- y el de los fenómenos ya iluminados, orden racionalizado, ámbito propicio para la maniquea pugna entre sueños y vigilia, y todo cuanto desde esta dualidad se proyecta. ${ }^{22}$

\footnotetext{
Señala al respecto Arnulf Rainer: "His later works, the finger-paintings, reveal such a degree of seriousness and absoluteness which is known only to religious art. He showed human suffering in a particular forceful way" (MENNEKES, Friedhelm., ARNULF, Rainer, “About Louis Soutter" en Louis Soutter, op. cit. p. 53). Por su parte, Thévoz no deja de señalar que estas figuras "échappent au temps profane et aux significations pratiques: ells sont comme irradiées para le rêve” (THÉVOZ, Michel. Louis Soutter. Rencontre Lausanne, Lausanne, 1970, p. 106).

22 En ello Lacan nos expone su propia comprensión del fenómeno en tanto que alude directamente a lo forcluido para señalar el lugar en el que, en esta terrible tensión entre razón e instinto, queda nuestro material primordial reprimido o borrado, anulado. Lo forcluido, para el psicólogo francés, permanece fuera incluso de lo inconsciente. Esto es, siendo fuer-
} 




Fig. 2. Danza ritual, Roca dels Moros, Cogull, Lleida. Neolítico.

Este artista, el creador de naturaleza órfica, permanece en su estrato esencial y advierte la imposibilidad de comunicarse certeramente con el mundo exterior, con el mundo de imágenes proyectadas desde las honduras. ${ }^{23}$ Eco de ello, sin ir más lejos, lo encontramos muy lúcidamente expresado en el Orfeo (1950) de Cocteau. Si nos fijamos en aquello que, por cercanía con este último, nos presenta Picasso algunos años antes - precisamente en la época más productiva de Soutter, esto es, al inicio del segundo tercio de siglo-, es el simbolismo del minotauro. Lanzamos simplemente la idea con el afán de presentar un interesante vínculo. Cabe comprender, a la hora de proseguir con la noción de una distancia gradualmente más amplia entre el reino de lo primigenio - no conceptualizado-y el de lo cultural, que allí donde en Lascaux -o en cualquier otro arte asentado o residente en un estrato mágico- se establece una identidad entre creador y chamán y, en consecuencia, una relación de proximidad entre el creador y el mundo de las deidades -cuyo mensaje queda en la película de Cocteau entrecortado, some-

za constitutiva del ser queda, sin embargo, abolido. Desde esta situación de desconexión con lo aparente parte el creador que se ha excedido en la búsqueda de límites de su imaginario.

23 Advertimos en ello una relación con cuanto Stoichita comprende como inversión del mundo platónico a la hora de tomar, en el Prometeo y en El comienzo del mundo de Brancusi, la sombra como lugar de fuerza, realidad protofenoménica (STOICHITA, Victor I., Breve historia de la sombra, Siruela, Madrid, 1999, p. 202). En este caso, el mundo de objetos, el mundo iluminado y existente, se presenta como copia apagada de la aludida primera realidad, realidad de sombra, pulsional, todavía no fragmentada. De ello partíamos al inicio de estas páginas a la hora de hablar de la cualidad de la sombra en la obra del artista suizo. tido a constantes interferencias-, en nuestra sociedad moderna delata una ruptura con lo racional puesto que por una parte el orden de lo telúrico carece de sustancia espiritual y, por la otra, dicho orden ni tan siquiera encuentra cabida en nuestro imaginario.

De este modo, mientras que en un momento no disociador, arcano, precultural, el creador no sólo es respetado sino que se precisa de su participación activa en la sociedad para el correcto funcionamiento de ésta - de manera que se le reintegra y hasta se le exige su participación en el orden de lo 'existente'-, en nuestra sociedad aparentemente sana -mera fachada, realidad insustancial en tanto que todo lo que remite a un orden profundo queda desterrado- ${ }^{24}$ la figura del creador-chamán queda desplazada, sepultada, delatándose con ello una preocupante desvinculación con un estrato telúrico, reparador. Nuestro orden cultural se presenta, en consecuencia, dada esta ausencia de pilares, presto a desmoronarse. Aquello que remite a un poso cualitativo se ve alejado de la vida en la medida en que se toma como dañino para una sociedad no necesitada de dioses sino meramente de crecimiento numérico. Este crecimiento, sobra decir, sólo se logrará fragmentando más y más un estrato de realidad, atomizándolo, iluminando toda sombra por cada uno de sus ángulos -en ello advertimos la diferencia entre el icono, pleno de contenido, y el holograma, en principio vacío y advertido como realidad insustancial-. Roto el hilo, diremos ahora con el deseo de regresar al punto del que partíamos, estas formas presentadas por Soutter quedan definitivamente alejadas de nuestro espacio convencional a modo de interpretaciones de un fenómeno sólo existente en el alienado mundo del creador.

Relacionar estas sombras con el mito de la caverna se comprende como solución natural dado que es a este mito adonde nos lleva una primera apreciación del objeto presentado. Con todo, conviene realizar una ligera aclaración, resaltar una variante, dado que a nuestra mirada, la que desde la obra de Soutter deseamos proyectar, es la sombra misma, como venimos

24 Preparándose con ello un estado de neurosis. Por otra parte, resulta de interés la distinción entre lo sano y enfermo realizada por Földényi (FÖLDËNYI, László. F., Melancolía, Galaxia Gutenberg, Barcelona, 2008.), quien retoma las ideas ya propuestas por Nietzsche y Thomas Mann en torno a la materia. En la misma línea y como precursor directo de estos últimos, la comprensión de Schopenhauer al respecto resulta esclarecedora. 
diciendo, la que genera el mundo de formas "vivas' y no al revés. Por lo demás, desde nuestra perspectiva, como en Platón, encontramos en la caverna a ese mismo sujeto diurno. Desde esta posición el orden en verdad falseado no es el que habita y presenta Soutter sino aquél común al aludido sujeto. Siendo así el lugar natural de todo creador el estrato telúrico o mundo de verdades esenciales, y resultando evidente que el sujeto se ha perdido en su cegadoramente iluminado laberinto, no nos queda sino aceptar que su mensaje nos llega ausente de significación y que el motivo por el que nos resulta inaccesible, hermética, la voz del creador, radica en que no participamos de su mismo imaginario, de su misma visión de lo real, sino que ésta, al contrario de lo que usualmente venimos a considerar, se comprende como errónea, como falsa.

El horizonte presentado por el artista escapa a nuestros sentidos, a nuestra lógica, para constatar lo limitado de nuestro acercamiento a la realidad, para denotar que aquello que nos alcanza en forma de ruido - la partitura de Holliger- no es sino nuestro modo de percibir racionalmente una verdad de naturaleza más honda -como acontece en la aludida película de Cocteau con los mensajes llegados del inframundo-, no mutilada, existente en el cosmos del creador y comprendida por nosotros como esquizofrénica al no encajar su 'lógica' en aquélla desde la que habitualmente nos manejamos. ${ }^{25}$ Negativos de una realidad interior,

25 En un pasaje de su conocido estudio, Prinzhorn se muestra certero en su entendimiento del llamado arte alienado: "Quien no crea en poderes sobrenaturales tampoco tendrá nunca apariciones deseadas o ninguna en absoluto, y quien no haya tenido apariciones tampoco posee ninguna prueba de su fe y sólo seguirá construyendo dudosamente, sin fundamento, y mientras la existencia humana lo acompañe mirará en la noche, muerta para él, sin que el ruido de un ángel envuelto en pesada seda inclinándose sobre su cama pueda probarle la existencia de un alto poder celestial, y mucho menos que la alta corona que día y noche se cierne sobre todos los hombres se despliega para él. De muy buen grado creo tener el anhelo de querer saber qué aspecto tienen vuestros invisibles compañeros protectores y sobrenaturales soberanos del mundo. Pero estoy firmemente convencido de que posibles envidiosos renunciarían pronto al deseo si supieran a qué enorme sufrimiento van unidos tales encuentros. Sin gran sufrimiento no hay en la Tierra grandes alegrías. Es fácil demostrar por qué sólo las personas que están acostumbradas a luchar entre la vida y la muerte con una sonrisa y pueden afrontar su meta sin temor se ven principalmente honradas con gratas apariciones, señales y visitas" (PRINZHORN, Hans, Expresiones de sombras de un ordenamiento no sujeto a la lógica: éste es el mundo que Soutter revela como testimonio amargo de una realidad de cuyo orden lumínico ha sido exiliado. Habiendo descendido a profundidades preculturales, Soutter, prototipo del creador moderno, no encuentra ya el camino de regreso al reino de las imágenes diurnas. Su situación como ser, no como creador o exponente de símbolos, deviene agónica.

\section{Dioses liberados, dioses exiliados}

Como ya en parte hemos realizado, resulta inevitable valorar la expresión estética de Soutter a partir de episodios concretos de su vida. Desde esta consideración, sin ir más lejos, la abundancia de mujeres convulsivas en sus pinturas viene comúnmente a vincularse con el poso dejado por Magde en el ánimo del pintor. ${ }^{26}$ El matrimonio, recordemos, quedó dramática y abruptamente roto en el año 1903. Con todo, más que uno u otro hecho concreto, cuanto denota esta pintura es una incapacidad por parte de Soutter acentuada conforme el transcurrir de los años a la hora de compatibilizar los distintos estratos de realidad. Este fenómeno neurótico en inversa correspondencia con la neurosis colectiva de un mundo agotado por su alta racionalidad-, esta escisión de su personalidad, será lo que acabará por llevar a la familia del artista a internarlo en una residencia de ancianos, según hemos dicho, contra su voluntad en 1923. Siguiendo desde aquí la línea exageradamente causal, racional, mecánica, que Zola establece a la hora de concatenar rasgos heredados por los personajes de su Rougon-Macquart, podríamos divagar fantasiosamente para exponer que así como Soutter manifiesta con su pintura una imposibilidad de aunar mundo interior y mundo exterior - no nos atrevemos a decir mundo emocional y mudo racional en la medida en que este último existe, desde otros patrones, en el horizonte del artista-, por su parte Le Corbusier, como se ha dicho primo de Soutter y en cierta medida artífice de la recuperación de su obra, atesoraría para sí la capacidad de dotar de

la locura. El arte de los enfermos mentales, Cátedra Madrid, 2012, p. 291).

26 "La mujer ocupa un lugar privilegiado, como figura maternal protectora pero también como figura demoníaca y religiosa" (SOLANA, Guillermo, "La suiza visionaria: Wölfli, Soutter, Aloïse”, en En torno al Art brut, VV.AA., Círculo de Bellas Artes, Madrid, 2007, pp. 92). 




Fig. 3. Louis Soutter. Souplesse, 1939. Musée cantonal des Beaux-Arts Lausanne

significado coherente ambos universos -apolíneo y telúrico o caótico, racional y emocionalpara así ofrecer una visión unitaria -e imponerla en parte incluso privilegiando así una nueva lógica estética- de su caudaloso mundo. Esto último se expone, sobra añadir, a modo de relato simbólico aprovechando que la propia experiencia de Soutter y la evolución con tintes fáusticos de Le Corbusier recoge perfectamente el devenir de la estética contemporánea, de la cultura contemporánea, con sus restricciones, sus nudos, y sus en mayor o menor medida convincentes respuestas a sus interrogantes. Más que considerar a Le Corbusier un arquitecto técnicamente excepcional, cabe destacar de él -como ocurre con Soutter en relación con la pintura- aquella genialidad que le convierte posiblemente en el más destacado arquitecto del pasado siglo, sin que haya contradicción en ambas afirmaciones.

Volviendo desde esta distinción a una idea anteriormente apuntada, diremos aún que lo que en un periodo primitivo o sin ir más lejos en el medievo es tomado como visión, como capacidad positiva del sujeto creador, se pre- senta a nuestros ojos como cualidad simbólicamente ineficaz, entiéndase bien, como mera expresión estética y no ya como mensaje lanzado desde unos órdenes de realidad asentados sobre niveles preracionales si bien válidos a la hora de interpretar y dotar de sentido una realidad. La perenne relación entre arte y enfermedad, diremos pues el terreno en que ahora nos situamos así lo demanda, se acentuará de forma definitiva en el Romanticismo como muestra de la imposibilidad del sujeto para adecuar, a escala masiva, un orden natural y un horizonte eidético. Hölderlin expondrá con nitidez el resultado de este destierro de lo divino, o si se prefiere del destierro del componente telúrico, irracional, de lo divino, lo que provocará el inevitable apagamiento completo del símbolo.

El sujeto creador, en cualquier caso, se obceca por naturaleza en rescatar la sustancia telúrica y llevarla hasta la superficie. De producirse satisfactoriamente el encuentro, lo substancial se integrará óptimamente en la realidad y en este caso el mundo de hechos concretos quedará incorporado dentro de una esfera más amplia capaz de aunar diferentes estratos exis- 
tenciales. ${ }^{27}$ Todo ello se presenta, sin embargo, casi como una imposibilidad en nuestro espacio actual para desasosiego no sólo del creador sino, de modo más inconsciente, de ese sujeto anclado a unos niveles de existencia aparentemente menos conflictivos. La pintura de Soutter, lejos de aunar los polos existenciales desde los que habitualmente nos comprendemos, expone el destierro de los dioses, el destierro asimismo del artista, la lejanía de ambos pues en nuestro mundo racionalizado ni los unos ni el otro encuentran ya cabida. Se ilumina así una renuncia, se torna a su vez evidente nuestra incapacidad para participar de un sentido remoto de existencia, encerrados como nos vemos en nuestro estrecho mundo dominado por la lógica. De lanzarnos a conjeturar la naturaleza de las sombras observables en la obra del artista suizo, diríamos que esas figuras no son ni presencias recogidas de su mundo cotidiano ni tan siquiera proyecciones del pintor, sino ante todo divinidades caídas en desgracia, modernos dioses empequeñecidos hasta la ridiculez, modernos héroes agonizantes dada su imposibilidad de aflorar en un orden consciente, lumínico, de existencia, divinidades trágicamente imposibilitadas de complementarse con su contraparte solar. Dioses, en fin, exiliados.

Desde aquí, con todo, podemos descubrir una veta luminosa, un camino a seguir a la hora de profundizar en el imaginario de Soutter. Si bien no nos adentraremos por estas lindes ahora que vamos cerrando estas líneas, dejamos indicados algunos de estos presupuestos que pueden complementarse o imponerse sobre lo que en estas páginas hemos mencionado. El primero de ellos nos lleva a tomar estas figuras como dioses simbólicamente liberados de la metafórica cruz, liberados de ella si bien encerrados en unos espacios nocturnos -oscuridad devenida ante todo del eclipse que el sujeto racional provoca dada su renuncia, su incapacidad, para tender un puente entre un es-

27 Con todo, frente a la necesidad consustancial al sujeto, prenatal incluso, de vincularse a una esfera en la que permanecer a salvo, se alza un orden 'externo' amenazante contra el que el individuo no puede en modo alguno luchar. Ninguna mampara o sistema, por perfecta y racionalmente construida que parezca, le ofrece al sujeto un consistente estado de seguridad. Sloterdijk subraya este hecho en su obra magna: "Sea lo que sea siempre lo que se afirme como interior aparecerá cada vez con mayor evidencia como el interior de un exterior" (SLOTERDIJK, Peter, Esferas I, Siruela, Madrid, 2003, p. 78). trato diurno y otro nocturno-. En este caso no habremos necesariamente de aludir a un ethos melancólico al uso, una pulsión neorromántica impregnada de sentido de caída, sino que más bien, atendiendo al ocasional gesto de euforia de las figuras, comprendemos que más que haber quedado enfangado el creador en un terreno nocturno, saturnal, cuanto hallamos es una deliberada reclusión en un espacio provisto de una tensión vital efervescente, poderosa, jubilosa incluso, si bien alejado de nuestro mundo diurno. ${ }^{28}$ Efectivamente, más que un estado de apatía, de tedio o pulsión avital, advertimos -y esto es común tanto en el Art brut como, en general, en el llamado arte alienado-, una energía creativa en absoluto fijada: el artista, expulsado del mundo diurno, denodadamente busca un espacio en el que dar forma, sacar de sí, su particular visión de las cosas. Así, frente al decaimiento, frente a la postración de un orden existencial simbolizado por la cruz en los momentos de mayor sentido agónico, los dioses que Soutter nos presenta en tantos otros instantes se revelan rebosantes de dinamismo, energía y, si no deseosos de salir a la luz, al menos sí deseosos de hacer de su espacio un mundo conforme a sus necesidades y en el que no se vean molestados por cadenas racionales.

Regresando a lo apuntado antes de esta última interpolación, desde aquí habría de realizarse una vinculación entre dicha caída o permanencia en la oscuridad, y la figura del artista moderno. En otras palabras, Soutter se presenta en cierto modo como Cristo crucificado, se solapa con él y con la cruz. ${ }^{29}$ Este quedar recluido en un orden aislado del mundo real, en los mo-

\footnotetext{
28 Establecemos con ello una distinción. Lo diurno, desde una mentalidad polarizada, se llega a comprender, como en los lienzos de Giorgio de Chirico, a modo de espacio tedioso, alejado de lo dionisiaco, un mundo, en fin, aplastado por el sol hasta presentarlo desde un plomizo estatismo. Aquello presenciado por el residente en este mundo aparentemente iluminado es mera imagen del mundo de realidades profundas del que toma parte el creador, es pura cáscara. Por su parte, una distancia respecto de un orden vivo, orgánico, acompañada de un deseo de vínculo entre ambos mundos, queda expuesta en la obra, por tomar un ejemplo de otro creador altamente simbólico, de Chagall. Este deseo de vínculo, con todo, no dejamos de encontrarlo asimismo en el aludido de Chirico, quien pintará incluso cordones umbilicales denotando de modo patente el deseo de unir ambos planos existenciales.

29 "The cross as the silhouette of the human. The human as the silhouette of the cross. [...] they transform into each other, reciprocally" (MENNEKES, Friedhelm, ARNULF, Rainer, “About Louis Soutter" en Louis Soutter:
} 
mentos de cese de efervescencia vital, se expone mediante la visión de esa figura redundante en su trabajo que es la sombra crucificada. A partir de aquí un estudio simbólico resulta pertinente pues, pese a que por lo común observamos en la obra del pintor suizo al crucificado (Cristo, Soutter -y por derivación el creador contemporáneo-), iluminado por un sol oscuro, sol negro -por retomar la imagen de Nerval, Kristeva y tantos otros,$-^{30}$ en otras imágenes

Fingermalereien 1937-1942, Galerie Karsten Greve, Köln, 1998, p. 53).

30 La idea de un dios que es a un tiempo sol y oscuridad, si bien nos puede perfectamente llevar hasta el epicentro de la cábala, así como hasta todo estado elemental no disociado de lo real -en sintonía con el valor del símbolo y con el valor del lenguaje en momentos previos a la adquisición de un grado concreto de abstracción-, nos remite a Pico della Mirandola. A él aluden Panofsky y Klibansky cuando, en su Saturno y la melancolía, leemos que "Según Pico della Mirandola, la posibilidad misma de llegar a ser un dios o una bestia era lo propio del hombre; y la propia situación sobre la estrecha cresta entre las dos 'simas', que se reconocía cada vez más claramente como la característica principal del hombre saturnino y melancólico, parecía a esas personas elegidas, por su misma peligrosidad, elevarlas por encima del nivel seguro pero gris del vulgo" (KLIBANSKY, Raymond, PANOFSKY, Erwin, SAXL, Fritz, Saturno y la melancolía, Alianza, Madrid, 2016, p. 249). En un reciente artículo, María José Vega hace referencia a la idea de Dios como luz y tiniebla en referencia asimismo a Pico della Mirandola (VEGA, María José, "La solitaria oscuridad del padre. El Dios de las tinieblas en la Oratio de dignitate hominis" en Quaderns d'Italià, vol. 6, 2001, pp. 195-200). En lo que toca a la cábala, y no nos separamos por tanto de Pico, podríamos proponer la imagen del sueño de un dios que se hace luz en el hombre o, siguiendo a Moshe Idel, aludir a una inversión: "Quisiera recordar brevemente el empleo normal de esa metáfora -el hombre como sombra de la Divinidad- para destacar la esencia de la 'inversión' cabalística. Según la interpretación de un proverbio asirio, 'el hombre es la sombra del dios y los hombres son la sombra del hombre; el hombre es el rey, que es como el espejo del dios'. El hombre es, pues, la sombra de una sombra, o, por interpretarlo de otra manera, el protegido de otro protegido" (IDEL, Moshe. Cábala. Nuevas perspectivas, Siruela, Madrid, 2005, p. 247). Inmediatamente después, Idel pone en relación esta idea con un comentario gnóstico en el que se lee que los eones le dicen a Barbeló que cada uno de ellos es una sombra de él mismo, de Barbeló, que no es sino sombra de un Dios primero. Todo ello nos ayuda a comprender que el aura bizantina, en nuestra época velada, melancólica, perfectamente deviene en sombra en tanto que señala, precisamente, a la sombra de una sombra. Enlazamos de nuevo esta noción con la del eclipse de Dios de Buber y con del sí-mismo de Jung. En lo que nos interesa, queda la opción de que estas sombras vinculen al ser no con la divinidad de Buber sino con el sí-mismo de Jung, si bien aquí se abre la disyuntiva entre si este sí-mismo ha de comprenderse como divinidad o como proyección de ésta a modo de presenciamos al astro envuelto en otras tonalidades, lo que se comprende como un síntoma de movimiento anímico. En tal caso advertimos un indicio de alejamiento del nadir que asimismo podemos extrapolarlo al creador contemporáneo, a un primer momento de superación del ethos melancólico. No siempre ocurre de este modo, no obstante, y en otras ocasiones cuanto observamos es una doble pulsión simbolizada por la aparición de un astro nocturno y uno diurno, denotándose con ello ya un estado de enfrentamiento, ya una conexión benigna entre ambos polos cósmico-existenciales.

Este último aspecto, y ello no resulta ni mucho menos despreciable, se muestra reiteradamente, según hemos comentado en una anterior nota al pie, en la obra de Giorgio de Chirico, ${ }^{31}$ en este caso, sin embargo, desde una perspectiva solar cegadora. Por último, un contraste entre parte del vasto imaginario de Chagall y el de Soutter resulta esclarecedor, pudiéndose en cierto modo comprender la obra del uno como negativo de la del otro. Así, prescindiendo de matices, mientras el pintor de origen bielorruso participa ante todo de una visión diurna y el suizo de una nocturna, cada una de ellas remite a un distinto estado de idealidad onírico y distanciado del mundo fenoménico. En este sentido, frente a un Chagall que elude todo marco histórico elevándose hacia lo alto, Soutter se recluye en su soterrado mundo. Con estas últimas líneas simplemente hemos querido exponer unas hipotéticas pautas de estudio ya sea para retomarlas en posteriores trabajos, ya para su desarrollo por quien lo comprenda pertinente. Motivos de apoyo para ello, al margen del significado de crucifixión, son el carácter de icono -en un caso aureolado, en el otro oscurecido- del que ya hemos hablado y del que toman parte ambos creadores -la sombra como

demiurgo. La presencia de la sombra en nuestra época, en cualquier caso, parece exponer una cuestión general que es la del velo de lo absoluto, señalando sin embargo ese velo, justamente, lo absoluto. Por lo demás, la ambivalencia de la propia creación nos invita a adoptar el punto de vista que más se ajuste a nuestra visión del mundo.

31 También podríamos fijarnos en otro artista melancólicamente solar como van Gogh, en concreto en el dominio que el sol, el girasol asimismo como equivalente de aquél, ejerce sobre su persona, y que desvela asimismo un sol disimuladamente oscuro aun desde su radiante luminosidad. Luminosidad que acaba, en su obsesión por mirarlo con fijeza, por cegar la visión y la razón. No cabe despreciar, en este punto, la tradicional asociación entre el amarillo y un pathos enfermizo.$$
\text { ciacion entre el amarillo y un pathos enfermizo. }
$$ 
aura del sujeto moderno-, o la figura del doble, dominante en Soutter y abundante en Chagall sin que quepa en ocasiones afirmar cuál es la figura que se mueve en un mundo irreal y cuál en el supuestamente real, de haberlo y si es que cabe establecer diferencias tajantes al respecto.

\section{Conclusión}

El mundo de sombras presentado por Soutter, según hemos podido advertir, viene a sintetizar y a simbolizar la condición de nuestra propia mirada, restringida a comprender estos espacios, estas sombras, como figuraciones de una enajenada realidad; una mirada, la nuestra, incapaz de conceder a estas formaciones del espíritu un valor denso, un valor no meramente estético sino ante todo numinoso, apto para cohesionar realidades en principio disonantes. La mirada del espectador se revela en estos momentos crítica en tanto que a menudo tiende a medir estas realizaciones del espíritu desde su proyección formal y no ya desde su comprensión como un lenguaje que nos habla y nos apremia aun cuando no podemos escucharlo, mundo de formas y sonidos inconexos, deshilvanados. Incapaces de desproveernos aun en menor grado de nuestra mampara racional, no reparamos en que la expresión de Soutter procede de un estrato desterrado de nuestra propia naturaleza.

Nuestra percepción, como herramienta de un complejo organismo, permanece sólo atenta a aquello que alimenta nuestro orden pretendidamente cultural, atenta exclusivamente hacia lo que ayuda a clasificar y racionalizar, a comprender desde la estrechez y a menudo desde la parcialidad. Para un sentido de plenitud, en cambio, no parecemos estar preparados, y todo cuanto nos llega de esos otros mundos presentados por Soutter rápidamente lo echamos sobre el saco del mal, la locura o la muerte: con una sonrisa lo enterramos o lo ponemos a la venta, con la osadía de adjudicar su valor o cifrar el interés de estos trabajos desde la condición de enajenado del creador que las lleva a cabo. Todos estos conceptos, todas estas disecciones desde las que clasificamos lo inclasificable, en fin, resultan válidos para dejarnos momentáneamente tranquilos, para regresar del museo a casa con un gesto de alivio, de agradecimiento por recobrar nuestro espacio de normalidad, pero a su vez se delatan inválidos para conciliar polaridades, tensiones con las que diariamente entramos en contacto y nos mellan lo más íntimo de nuestro ser.

La voz del artista, la voz de Soutter, queda así definitivamente distanciada de la nuestra propia. Esos murmullos que nos presenta con su trabajo constituyen el sonido distorsionado de una realidad que no halla un fondo concreto donde proyectarse, que queda engullida en un interior cada vez más soterrado como más y más superficial parece, en simetría, aquel exterior en el que el creador, su pintura, sus personajes, no encuentran ya espacio. Su obra, asentada sobre una mirada expresionista, incorporada felizmente para su recuperación, infelizmente para la profundización en ella, se revela ante todo como símbolo de unos tiempos que trascienden su momento, y presenta ante nuestra mirada aspectos de la condición natural y la deriva de nuestra propia existencia.

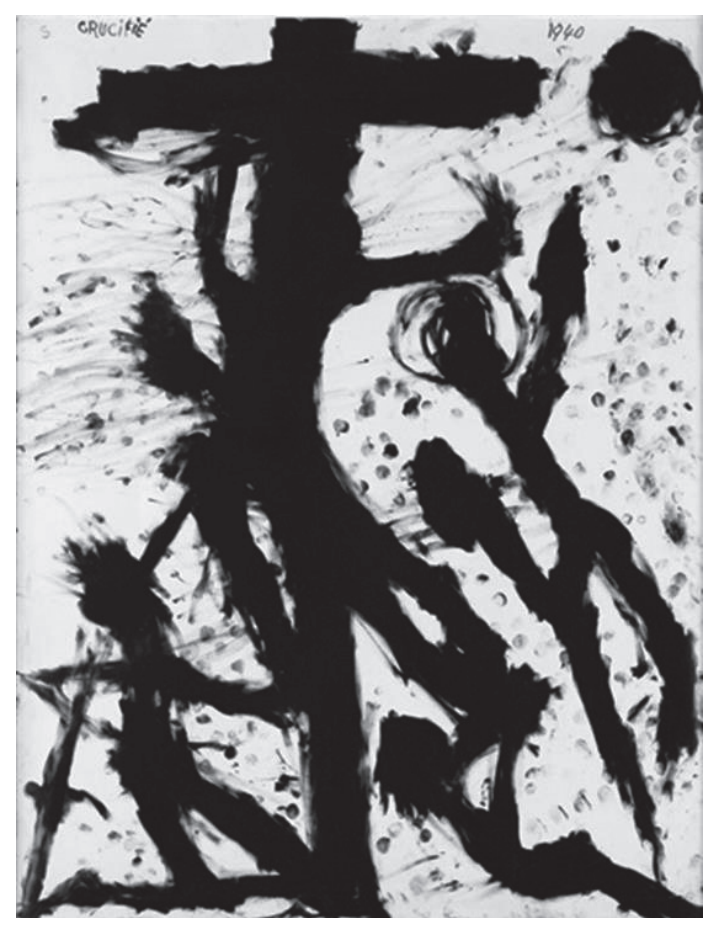

Fig. 4. Louis Soutter. Crucificié. La potence divine. 1940. Tinta sobre papel. 